\title{
La velocitat de reacció
}

\author{
Montserrat Tortosa \\ IES Ferran Casablancas (Sabadell), CRECIM-UAB \\ mtortosa@xtec.cat
}

Es presenta un experiment per determinar la velocitat d'una reacció i la seva evolució temporal, utilitzant sensors de pressió i temperatura $i$ un equip de captació automàtica de dades. Es un experiment senzill, adient per la química de Batxillerat, que pot ampliar-se per treballar les variables que afecten la velocitat.

Paraules clau: velocitat de reacció, sensor, pressió, reacció química, equip de captació automàtica de dades

\section{Introducció}

A la Unió Europea un 10 \% de la contribució industrial al Producte Interior Brut és aportat per la indústria química. L'activitat econòmica d'aquest sector es basa, naturalment, en processos químics i quan interessa dur a terme una reacció química a escala industrial un dels factors clau a tenir en compte és la velocitat de reacció. Una reacció massa lenta pot resultar econòmicament inviable, mentre que si és massa ràpida podria costar de controlar.

La velocitat de reacció és una magnitud que es defineix com la variació de la concentració d'un reactiu (o d'un producte) en un període de temps. Les magnituds que cal verificar per tenir la velocitat de reacció adequada depenen de cada cas.

Centrarem el nostre estudi en una reacció molt comuna que s'utilitza en àmbits diversos com per exemple en la neteja de la calç incrustada a les canonades d'aigua o en l'anàlisi de roques calcàries; és la reacció del carbonat de calci amb àcid clorhídric:

$$
\mathrm{CaCO}_{3}(\mathrm{~s})+2 \mathrm{HCl}(\mathrm{aq}) \rightarrow \mathrm{CaCl}_{2}(\mathrm{aq})+\mathrm{CO}_{2}(\mathrm{~g})+\mathrm{H}_{2} \mathrm{O}
$$

Com que s'obté diòxid de carboni, que és un gas, si fem la reacció en un recipient tancat podrem seguir l'evolució de la formació de productes mit- jançant un sensor de pressió. Si el volum i la temperatura es mantenen constants, la velocitat de reacció és proporcional a la variació de pressió:

$$
\begin{gathered}
v=\frac{\Delta\left[\mathrm{CO}_{2}\right]}{\Delta t} \\
v=\frac{\Delta P}{R T \Delta t}
\end{gathered}
$$

on $\Delta \mathrm{P}$ és la variació de pressió a l'interior del recipient deguda a la formació de $\mathrm{CO}_{2}$.

Per tant, cladrà fer la reacció en un recipient tancat, a temperatura constant (ambient) i mesurar les variacions de pressió al llarg del temps.

\section{Objectius}

- Aprendre a determinar velocitats de reacció

- Estudiar la variació de la velocitat amb el temps per a la reacció del carbonat de calci amb l'àcid clorhídric.

En acabar la pràctica l'alumnat ha de saber mesurar l'evolució de la pressió en una reacció química en que intervenen gasos i calcular velocitats de reacció a partir de variacions de pressió. 


\section{Material i equipament necessaris}

\section{Material de laboratori}

- Erlenmeyer de $100 \mathrm{ml}$

- Tap de goma per a l'erlenmeyer, travessat amb una agulla hipodèrmica.

- Suport, pinces i nou.

- Allargador de pressió Luer Lock (d'uns $8 \mathrm{~cm}$ )

- Pipeta de $10 \mathrm{ml}$

- Espàtula

- Balances

\section{Productes}

- $\mathrm{HCl} 0,25 \mathrm{M}$ A

- Calcita $\left(\mathrm{CaCO}_{3}\right)$ triturada amb el morter

\section{Elements equip Multilog}

- Interfície Multilog-Pro amb cables USB

- Sensor de temperatura (rang $-25^{\circ} \mathrm{C} / 110^{\circ} \mathrm{C}$, resolució $0,13^{\circ} \mathrm{C}$ )

- Sensor de pressió (rang 0-700 kPa, resolució $0,5 \mathrm{kPa})$

- Ordinador

\section{A Cal portar ulleres de seguretat}

\section{Muntatge i execució de l'experiència}

1) Es connecta el tap al sensor de pressió. Cal ajustar el sensor de pressió al tub allargador $\mathrm{i}$ aquest a una agulla hipodèrmica que travessa el tap de goma. Aquesta operació és molt important; no hi ha d'haver pèrdues ja que es faran mesures de pressió de gas (fig. 1).

2) Es posen $10 \mathrm{ml}$ d'àcid clorhídric $0,5 \mathrm{M}$ dins de l'erlenmeyer.

3) Es preparen $0,2 \mathrm{~g}$ de calcita $\left(\mathrm{CaCO}_{3}\right)$ en pols.

4) Es configura el sistema perquè enregistri les dades de pressió i temperatura en funció del temps. Per fer-ho cal seguir els passos següents:

a) Es connecta el sensor de pressió a l'entrada IO-1 i el sensor de temperatura a l'entrada IO-2 de la consola Multilog-Pro, i aquesta a l'ordinador mitjançant el port USB o el sòcol de 9 pins. b) Es clica el botó configurar ajudant

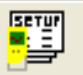

i s'obren successivament tres pantalles:

\section{Pantalla 1}

Es detectaran els sensors de pressió i de temperatura. En el cas que no surtin directament, caldrà buscar-los amb el menú situat a la dreta del seu nom.

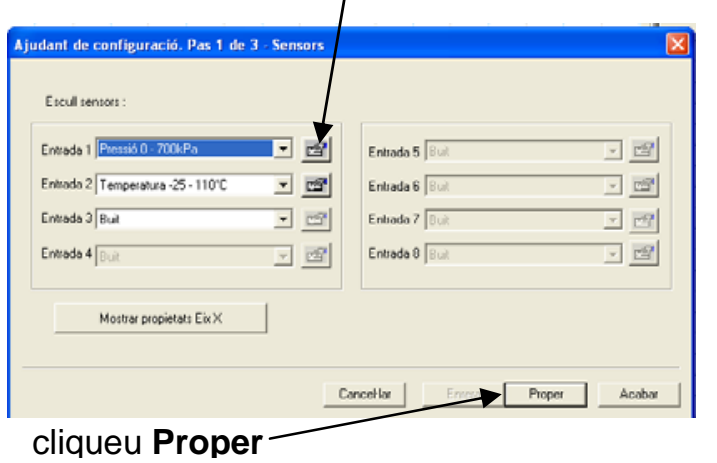

\section{Pantalla 2}

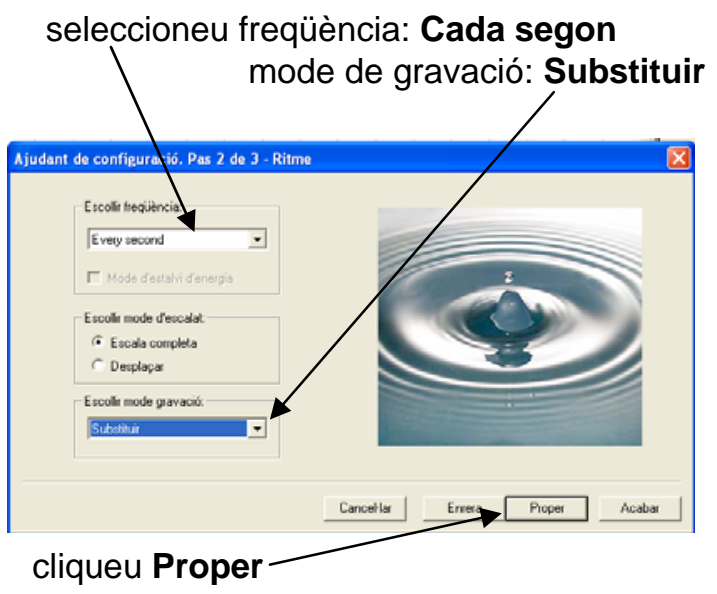

\section{Pantalla 3}

\section{Seleccioneu per temps 8:20 min.}

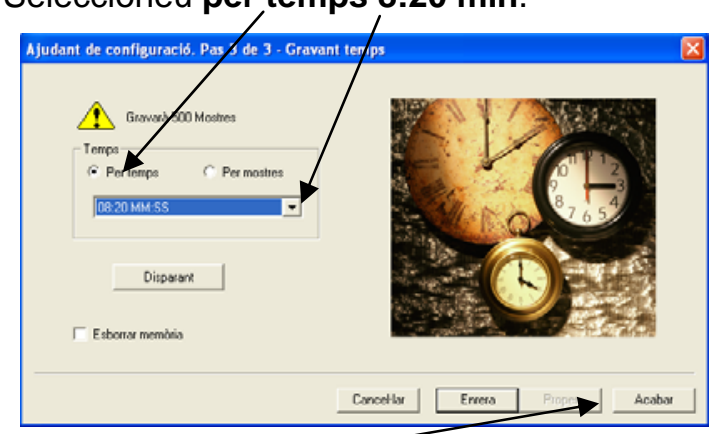

cliqueu Acabar 


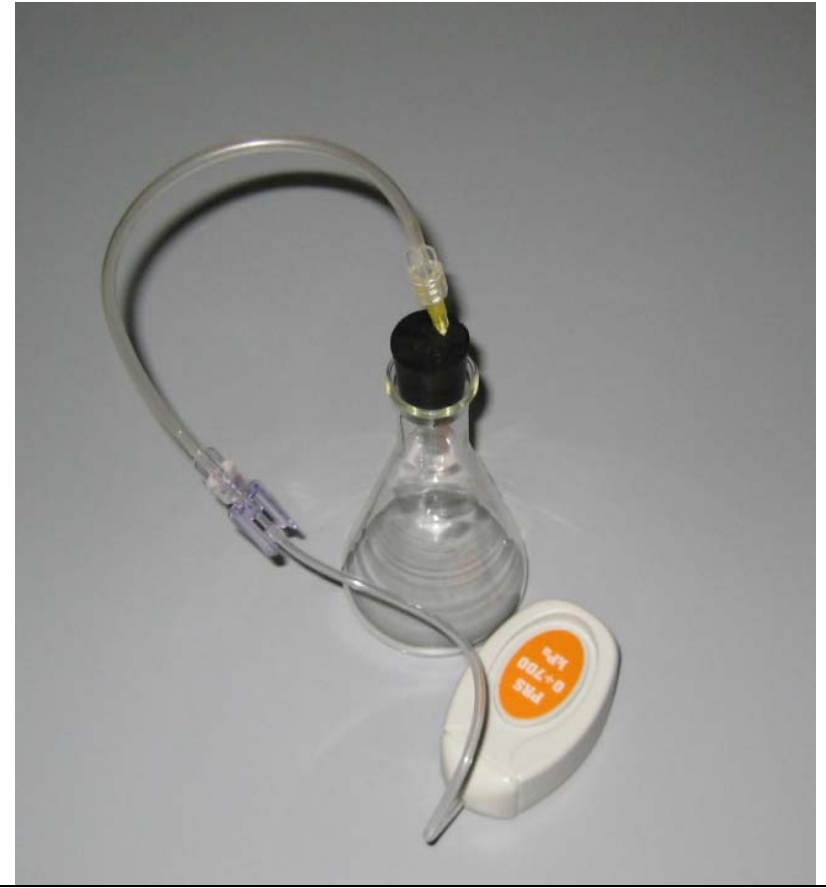

Figura 1. Muntatge experimental per a determinar velocitats de reacció amb equip MBL.

Alerta: Les operacions que cal fer a partir d'ara han de ser ràpides per no perdre gens del gas que es va produint a la reacció.

\section{Adquisició i}

\section{enregistrament de les dades}

1) Poseu en marxa el programa Multilab amb el botó executar

2) Aboqueu el sòlid a l'erlenmeyer i tapeu ràpidament amb el tap connectat al sensor de pressió.

3) Agiteu lleument l'erlenmeyer

4) Observeu i anoteu l'evolució de la reacció.

5) Quan vegeu que la reacció s'ha acabat, atureu l'adquisició de dades, amb el botó stop

Nota: La manca de pràctica pot fer que hi hagi pèrdues de gas per les juntures. Si fos així caldrà repetir l'experiència.

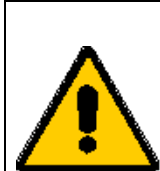

La dissolució que queda després de la reacció podeu llençar-la a la pica, deixant rajar aigua abundant.

\section{Resultats esperats.} Anàlisi de les dades

a) Si cal, ajusteu els valors dels eixos, de manera que el gràfic ocupi tota la pantalla (poseu-vos sobre l'eix horitzontal i premeu el botó dret, desactiveu l'opció autoescalat i canvieu els valors mínim i màxim per a poder veure bé el gràfic)

b) Observant la forma del gràfic i els valors de la taula es poden respondre qüestions sobre si la quantitat de gas produiit és constant durant la pràctica, quant temps dura la reacció, o quant valen la pressió i la temperatura inicials i a què són degudes.

c) També es poden calcular les velocitats de reacció a diferents intervals, treure conclusions sobre la variació de la velocitat al llarg del temps

Presentem els resultats obtinguts i el càlcul de la velocitat de reacció en tres intervals, un a l'inici, un al mig i el tercer al final de la reacció.

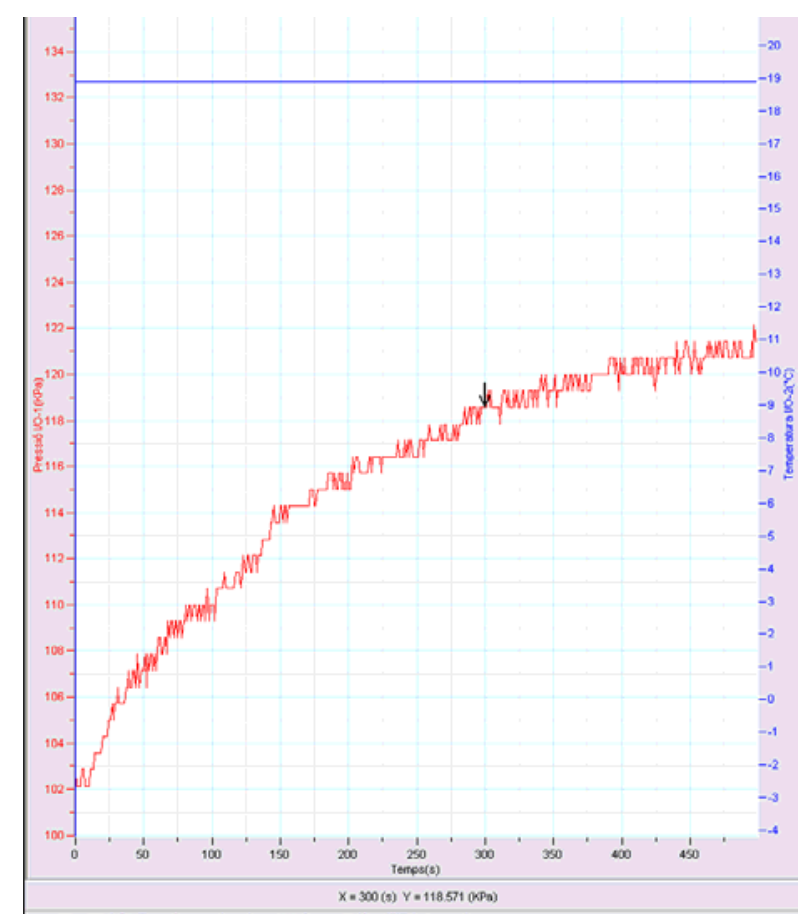

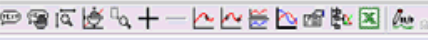

Figura 2. Gràfic de pressió (línia vermella) en funció del temps obtingut en fer reaccionar $10 \mathrm{ml} \mathrm{HCl}$ $0,5 \mathrm{M}$ amb $0,2 \mathrm{~g}$ de calcita triturada.

\section{Càlculs}

Amb la funció commutar primer cursor s'obté la fletxa de la figura que, en moure-la amb el ratolí pel gràfic, permet conèixer els valors de pressió i de temps que s'han recollit a la taula següent i amb els 
quals s'han calculat les velocitats de reacció. La temperatura $\left(T=18,9^{\circ} \mathrm{C}\right)$ és l'ambiental, línia blava al gràfic.

\begin{tabular}{|l|c|c|c|}
\hline \multicolumn{1}{|c|}{ Interval } & $\begin{array}{c}\text { A l'inici de } \\
\text { la reacció }\end{array}$ & Al mig & Al final \\
\hline $\begin{array}{l}\text { Temps } \\
\text { inicial / s }\end{array}$ & 0 & 150 & 300 \\
\hline $\begin{array}{l}\text { Temps } \\
\text { final /s }\end{array}$ & 150 & 300 & 450 \\
\hline $\begin{array}{l}\text { Pressió } \\
\text { inicial /Pa }\end{array}$ & $1,02 \cdot 10^{5}$ & $1,14 \cdot 10^{5}$ & $1,19 \cdot 10^{5}$ \\
\hline $\begin{array}{l}\text { Pressió } \\
\text { final /Pa }\end{array}$ & $1,14 \cdot 10^{5}$ & $1,19 \cdot 10^{5}$ & $1,20 \cdot 10^{5}$ \\
\hline $\begin{array}{l}\text { Velocitat } \\
\text { de reacció } \\
\text { /mol (L.s) }\end{array}$ & $3,30 \cdot 10^{-5}$ & $1,37 \cdot 10^{-5}$ & $2,74 \cdot 10^{-6}$ \\
\hline
\end{tabular}

Taula 3. Resultats experimentals i calculats en la reacció de $10 \mathrm{ml} \mathrm{HCl} \mathrm{0,5} \mathrm{M}$ amb 0,2 g de calcita triturada.

Dels resultats es desprèn que la velocitat de reacció va disminuint al llarg del temps.

\section{Propostes d'ampliació}

Aquest experiment és útil per treballar el control de variables que afecten la velocitat de reacció.

Si els alumnes coneixen la teoria de les col.lisions, se'ls pot proposar el disseny i execució d'experiments adients per fer variar la velocitat de reacció.

\section{Bibliografia}

Tortosa M (2005). Elaboració de guies didàctiques per a treballar a les aules de noves tecnologies per a les ciències. Llicència Depart. Educació (disponible a

http://phobos.xtec.es/sgfprp/resum.php?codi=89 3 consulta desembre 2008)

Tortosa M. (2008) L'aprenentatge de la química amb sensors. Casos pràctics, utilitat i valoració. Educació Química, n1. 45-50. Societat Catalana de Química (disponible a http://publicacions.iec.cat/repository/pdf/000000 52\%5C00000012.pdf consulta desembre 2008) 